\title{
Involvement of the Wnt- $\beta$-catenin pathway in invasion and migration of oral squamous carcinoma cells
}

\author{
SOICHI IWAI ${ }^{1}$, ATSUKO YONEKAWA ${ }^{1}$, CHIE HARADA ${ }^{1}$, MASAKAZU HAMADA ${ }^{1}$, \\ WATARU KATAGIRI ${ }^{2}$, MITUHIRO NAKAZAWA ${ }^{1}$ and YOSHIAKI YURA ${ }^{1}$ \\ ${ }^{1}$ Department of Oral and Maxillofacial Surgery II, Osaka University Graduated School of Dentistry, Osaka; ${ }^{2}$ Department \\ of Oral and Maxillofacial Surgery, Nagoya University Graduated School of Medicine, Nagoya, Japan
}

Received June 18, 2010; Accepted July 26, 2010

DOI: 10.3892/ijo_00000761

\begin{abstract}
The Wnt/ß-catenin pathway plays a critical role in cell proliferation and oncogenesis. To clarify the role of cytoplasmic accumulation of $B$-catenin in oral squamous cell carcinoma (SCC), the cDNA of a mutant form of B-catenin that lacks the entire region with the glycogen synthase kinase-3 $\beta$ (GSK-3ß)-specific phosphorylation site was transfected into $\mathrm{Ca} 9-22$ cells whose $\beta$-catenin had been expressed predominantly at the membrane, and permanent cell lines expressing aberrant $B$-catenin in the cytoplasm and nucleus were produced. These transfectants, C1 and C5, proliferated at similar rates to the parental $\mathrm{Ca} 9-22$ cells, but the cell morphology changed from polygonal to spindleshaped and close cell-cell interaction was lost. These mutant ß-catenin-expressing cells exhibited a significantly higher invasion/migration capacity than wild-type Ca9-22 cells. The transcriptional activities of this mutant $\beta$-catenin form was enhanced in these cells which could be demonstrated by an elevated level of the transcription factor T-cell factor (Tcf)/ lymphoid enhancer factor (Lef)-dependent reporter gene activity as well as by the up-regulation of Wnt/ß-catenin target gene matrix metalloproteinase (MMP)-7. Moreover, we observed the redistribution of E-cadherin, the rearrangement of actin filaments, and the elevation of active Rho family members, Cdc42 and Rac. These results suggest that aberrant cytoplasmic accumulation of B-catenin can induce Tcf/ Lef-mediated transcriptional activity, up-regulate MMP-7, and induce epithelial and mesenchymal transition (EMT). This would enhance the invasion and migration of oral SCC cells.
\end{abstract}

Correspondence to: Dr Soichi Iwai, Department of Oral and Maxillofacial Surgery II, Osaka University Graduated School of Dentistry, 1-8, Yamada-oka, Suita, Osaka 565-0871, Japan

E-mail: s-iwai@dent.osaka-u.ac.jp

Key words: B-catenin, cytoplasmic accumulation, cell invasion and migration, epithelial-mesenchymal transition, oral squamous cell carcinoma

\section{Introduction}

The Wnt signaling pathway, which is conserved in various species from worms to mammals, is involved in various differentiation events during embryonic development and leads to tumor formation when activated aberrantly. Wnt ligands bind to their cognate receptors on the cell surface and transduce signals through at least three distinct pathways: the canonical 3 -catenin pathway, the non-canonical planar cell polarity $(\mathrm{PCP})$ pathway and the $\mathrm{Ca}^{2+}$ pathway $(1,2)$. Among these intracellular cascades, the $B$-catenin pathway has been studied extensively, and abnormalities in this pathway lead to tumor formation and progression.

In the inactive state, when Wnt does not act on the cell, casein kinase Ia (CKIa) and GSK-3ß phosphorylate $\beta$-catenin in the Axin complex $(3,4)$. Phosphorylated $\beta$-catenin is ubiquitinated, resulting in the degradation of $\beta$-catenin by a proteasome and cytoplasmic B-catenin is kept at a low level (5). In the active state, Wnt binds to its cell surface receptor consisting of Frizzled and lipoprotein receptor-related protein $5 / 6$ (LRP5/6), and B-catenin escapes from phosphorylation by GSK-3ß and degradation in the Axin complex and, as a consequence, accumulates in the cytoplasm. The accumulated $B$-catenin is translocated to the nucleus, where it binds to the transcription factor T-cell factor (Tcf)/lymphoid enhancer factor (Lef), leading to up-regulation of $\mathrm{Wnt} / \mathrm{B}$ catenin target genes $(6,7)$, such as c-myc, cyclin D1, c-jun, metalloproteinase-1 (MMP-1) and MMP-7 (8-12). The most common molecular events occurring in tumor cells leading to a decrease in $B$-catenin degradation are mutations that inactivate APC, Axin or B-catenin $(13,14)$.

Under physiological conditions, the mucosa of the oral cavity exhibits membranous staining for $\beta$-catenin. In contrast, cytoplasmic accumulation of $\beta$-catenin is frequently observed in oral squamous cell carcinoma (SCC) tissues and cell lines $(15,16)$, although it is not closely associated with mutational alterations (17). This suggests that the deregulation of the $B$ catenin pathway and consequent overactivity of $\beta$-catenin may contribute to oral SCC progression. More recently, it has been shown that the activation of the $\beta$-catenin pathway is correlated with epithelial-mesenchymal transition (EMT) and invasiveness of cancer cells (18-20). However, some immunohistological studies of oral cancer failed to detect an association 
A

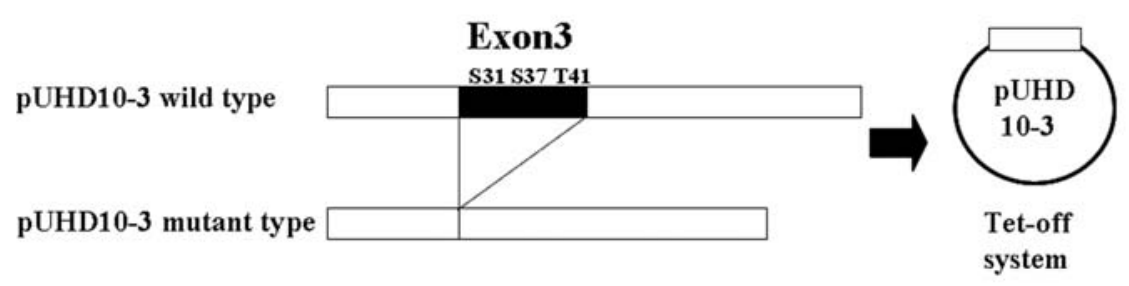

B

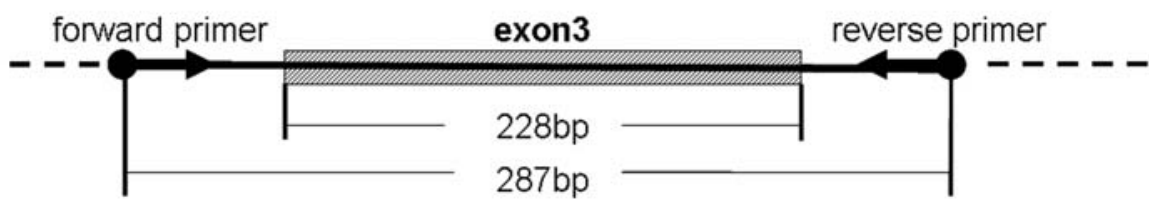

Figure 1. (A) Structural schema of wild-type and mutant-type B-catenin cDNA. Wild-type B-catenin cDNA containing the entire coding region and a mutated form of the B-catenin cDNA lacking exon 3 were cloned into pUHD10-3 vector under the regulation of a tetracycline-responsive promoter. The phosphorylation site specific to GSK-3B was included in the deleted region of the mutated B-catenin. (B) Structural schema indicating a pair of primers including the exon 3 region of $\beta$-catenin, which differentiated endogenous $\beta$-catenin (287 bp) and mutant $\beta$-catenin (59 bp).

between $\beta$-catenin expression and nodal metastasis $(21,22)$. To clarify the role of $\beta$-catenin in invasion and metastasis, it is essential to demonstrate the invasive behavior of oral SCC cells that overexpress the $\beta$-catenin gene in the cytoplasm. In the present study, this possibility was examined by introducing a mutated B-catenin cDNA that lacked the entire exon 3 including phosphorylation sites specific to GSK-3ß into Ca9-22 cells whose $B$-catenin had been expressed predominantly at the plasma membrane. The results suggest that aberrant cytoplasmic accumulation of $\beta$-catenin induces cellular alterations characteristic of EMT and enhances the invasion and migration of oral SCC cells.

\section{Material and methods}

Cell line and culture. The cell line Ca9-22 is derived from a well differentiated SCC (23) and was grown in Dulbecco's modified MEM (DMEM) with $10 \%$ fetal calf serum (FCS) at $37^{\circ} \mathrm{C}$ in a humidified atmosphere with $5 \% \mathrm{CO}_{2}$.

Transfection with $\beta$-catenin gene. The wild-type $\beta$-catenin cDNA containing the entire coding region and a mutated form of the $\beta$-catenin cDNA lacking exon 3 were cloned into a pUHD10-3 vector under the regulation of a tetracyclineresponsive promoter (Tet-off Gene Expression System). The phosphorylation site specific to GSK-3ß is included in the deleted region of the mutated $\beta$-catenin. These expression vectors, pUHD10-3 wild-type $\beta$-catenin and pUHD10-3 mutant $\beta$-catenin, were kindly provided by Dr Y. Nagasawa and Dr Y. Nakamura (24) (Fig. 1). Ca9-22 cells were transfected with the pUHD10-3 mutant B-catenin in combination with the pUHD15-1Neo vector using Lipofectamine Plus Reagent (Life Technologies, CA) and geneticin-resistant colonies were cloned, yielding cell lines including $\mathrm{C} 1$ and $\mathrm{C} 5$ that expressed mutant-type $B$-catenin. In this system, $B$-catenin expression was suppressed by treatment with $2 \mathrm{ng} / \mathrm{mg}$ doxycycline. Cell lines A1 and B19 were obtained by transfecting Ca9-22 cells with the empty vector (pUHD10-3) and the pUHD10-3 wild-type B-catenin vector, respectively, in combination with the pUHD15-1Neo vector.

RNA extraction and RT-PCR. A $0.5-\mu \mathrm{g}$ aliquot of total RNA was reverse-transcribed into single-strand cDNA and subsequent PCR was performed using a Takara RNA PCR kit (AMV) Ver. 3.0 (Takara, Shiga, Japan) by monitoring GAPDH levels as a quantitative control. The primer sequences used for PCR amplification were as follows: 5'-CAACTACATGG TTTACATGTTC-3' and 5'-GCCAGTGGACTCCACGAC-3' for GAPDH; 5'-CCAGCGTGGACAATGGCTAC-3' and 5'-TGAGCTCGAGTCATTGCATAC-3' for ß-catenin; 5'-AG ACTCCAGCGCCTTCTCTCCG-3' and 5'-CTGTGAGGAG GTTTGCTGTGGCC-3' for c-myc; 5'-TCTAAGATGAAGG AGACCATC-3' and 5'-GCGGTAGTAGGACAGGAAGTT GTT-3' for cyclin D1; 5'-AACTCCCGCGTCATAGAAATA ATG-3' and 5'-ACCCAAAGAATGGCCAAGTTCATG-3' for MMP7; 5'-GCATCAACACCATGAGTGGC-3' and 5'GAAGTCGGTCAGTTCCTTCC-3' for fra-1; 5'-CTGGAGC TTGAAAATCTGCCG-3' and 5'-GGTTTTTCGGTTCGTG AGTGC-3' for uPAR; 5'-AATGGGAAGTCCAGGCAGTGT ATC-3' and 5'-ACAGCGTTCTCCAGTAACAGCTG-3' for laminin-5 $\gamma 2$ chain; 5'-GGGTTTTTCGGTTCGTGAGT GC-3' and 5'-CCATTGGGCATCCAGAAGAGAGC-3' for MT1-MMP; 5'-CAAGTACTCGGGCAAAGAGG-3' and 5'-CTTCCTGGGCTGCTTATCTG-3' for S100A4; and 5'CAGTTCAAGACCGTGCAGAC-3' and 5'-TGGAACCTAC CCATCCCATA-3' for Wnt5a.

For MMP-7, sense primer: 5'-TGTATGCTGCAACTCA TGAACTTG-3', antisense primer: 5'-CATAGGTTGGATAC ATCACTGCATT-3' and probe: 5'-TTCTTTGGGTATGGG ACATTCCTCTGATCC-3'. For $\beta$-actin, sense primer: 5'-CC 
TGGCACCCAGCACAAT-3', antisense primer: 5'-GCCGA TCCACACGGAGTACT-3' and probe: 5'-ATCAAGATCA TTGCTCCTCCTGAGGGC-3'.

Western blotting. Extraction of proteins from cell lines and Western blot analyses were performed as described previously (17). Briefly, $10 \mu \mathrm{g}$ of total protein extracted from each of the three cell lines was electrophoresed, transferred to polyvinylidene difluoride membrane and visualized using a mouse anti- $\beta$-catenin monoclonal antibody (Transduction Laboratories, KY). Antibody binding was detected using an enhanced chemiluminescence kit (Amersham, Little Chalfront, UK).

Immunocytochemical staining. For immunocytochemical staining, cells were incubated with a mouse anti- $\beta$-catenin monoclonal antibody and then with goat anti-mouse secondary antibody conjugated to rhodamine. E-cadherin was stained using a mouse anti-E-cadherin monoclonal antibody and fluorescein isothiocyanate (FITC)-labeled goat anti-mouse $\mathrm{IgG}$ as the secondary antibody. For staining of actin filament, Alexa Fluor 546-conjugated phalloidin (Invitrogen, CA) was used. Fluorescent images were obtained using a confocal laser scanning microscope (Carl Zeiss, Germany) and processed using Photoshop software (Adobe).

Cell invasion and migration assay. To measure the cell invasion activity, transwell chamber assays were performed using a BD BioCoat Matrigel Invasion Chamber (BectonDickinson, MA). Cells were resuspended in serum-free DMEM and then added to the upper chamber at a density of $5 \times 10^{4}$ cells/insert. DMEM containing $10 \%$ FBS was added to the lower chamber. After incubation at $37^{\circ} \mathrm{C}$ for $48 \mathrm{~h}$, the number of cells that invaded into the lower chamber was counted. To measure the cell migration activity, transwell chamber assays were performed using BD BioCoat Cell Culture Inserts (Becton-Dickinson) in a similar manner as described for the cell invasion assay. A wound healing assay was also performed to determine the migration activity. The monolayer was scratched with a pipette tip. The cultures were incubated for $48 \mathrm{~h}$ and cells migrating over the exposed dish surface were observed.

Luciferase reporter gene assay. B-catenin/Tcf activity was measured using T-cell factor reporter plasmid TOPflash (Upstate, NY), which contains the Tcf-binding site upstream of the thymidine kinase minimal promoter and luciferase open reading frame. The FOPflash plasmid that contained mutated Tcf-binding sites was used as a negative control. Cells grown in 24-well plates were transfected with either $100 \mathrm{ng}$ of pTOPflash or $100 \mathrm{ng}$ of pFOPflash reporter constructs. TOPflash or FOPflash constructs were co-transfected with Renilla luciferase plasmid pRL-TK vector (Promega, WI) to normalize transfection efficiency. After $24 \mathrm{~h}$, cell lysates were collected and assayed for luciferase activity using a dual luciferase reporter assay system (Promega). Each experiment was performed in triplicate and repeated at least twice.

Real-time RT-PCR. The mRNA expression level of MMP7 and an endogenous housekeeping gene, $\beta$-actin, as an internal control, were quantified by real-time PCR analysis using
TaqMan technology. All primers and probes are depicted above. The fluorogenic probes contained a reporter dye (FAM) covalently attached at the 5'-end and a quencher dye (TAMRA) covalently attached at the 3'-end. TaqMan RT-PCR reactions were performed using an Excript RT-PCR kit (Takara) with a 7300 Real-Time PCR System (Applied Biosystems, CA). The primer sequences are indicated above.

GTPase activity assays. The activation of Cdc42, Rac1 and Rho GTPases was determined using a Cdc42, Rac1 and Rho Activation Assay Biochem kit (Cytoskeleton, CO). Briefly, cell lysates were incubated with a GST fusion protein corresponding to either the p21-binding domain (amino acid residues 67-150) of PAK1 or the Rho binding domain (amino acid residues 7-89) of Rhotekin, and the precipitates were bound to glutathione-coupled sepharose beads. Bound Cdc42, Rac1 and Rho were separated by SDS-PAGE and detected by immunoblotting with antibodies against $\mathrm{Cdc} 42$, Rac1 or Rho (Cytoskeleton). The bands were scanned and their intensities were quantified using the public domain ImageJ program.

\section{Results}

Expression of $\beta$-catenin and morphological changes in stable cell lines transfected with mutant $\beta$-catenin gene. An expression vector containing mutant $\beta$-catenin cDNA was transfected into Ca9-22 cells and 4 independent mutant-type cell lines were isolated. Two of them, C1 and C5, were subjected to further investigation, because of stable expression of the transfected B-catenin gene at high levels. RT-PCR analysis using a set of primers including exon 3 of $\beta$-catenin revealed the expression of endogenous $\beta$-catenin (287 bp) and mutant B-catenin (59 bp) in $\mathrm{C} 1$ and $\mathrm{C} 5$ (Fig. 2A). The proteins of endogenous $\beta$-catenin $(92 \mathrm{kDa})$ and mutant $\beta$-catenin $(84 \mathrm{kDa})$ were also detected in $\mathrm{C} 1$ and $\mathrm{C} 5$ cells by Western blotting (Fig. 2B). In the presence of $2 \mathrm{ng} / \mathrm{ml}$ doxycycline, the expression of mutant-type $\beta$-catenin was suppressed, indicating that the transfected gene was regulated under the Tet-off system (Fig. 2A and B). Mutant B-catenin was not demonstrated in the parental Ca9-22 cells, A3 cells, which were transfected with an empty vector pUHD10-3 and B19 cells, which were transfected with pUHD10-3 wild-type B-catenin gene.

In immunofluorescence analysis, cytoplasmic and nuclear B-catenin was detected in C1 and C5 cells, whereas B-catenin was located specifically at the cell membranes of the parental cell lines Ca9-22 and A3 cells (Fig. 2C). In the presence of doxycycline, the cytoplasmic accumulation of $\beta$-catenin in $\mathrm{C} 1$ and C5 cells disappeared.

$\mathrm{C} 1$ and $\mathrm{C} 5$ cells proliferated at similar rates to the parental Ca9-22 cells in the proliferation phase, when cells were seeded at low concentration ( $1.0 \times 10^{5}$ cells per 6 -well dish) (data not shown). Ca9-22 and A3 cells showed a polygonal shape and formed colonies with an intimate intercellular interaction, while cell lines $\mathrm{C} 1$ and $\mathrm{C} 5$ showed spindle-shaped morphology with cell processes and did not form colonies with a clean margin. Moreover, close cell-cell interactions were lost in these transfectants (Fig. 2D).

Enhancement of invasion and migration activities in the transfectants. The transfectants were subjected to invasion 
A

Doxycycline - Doxycycline+

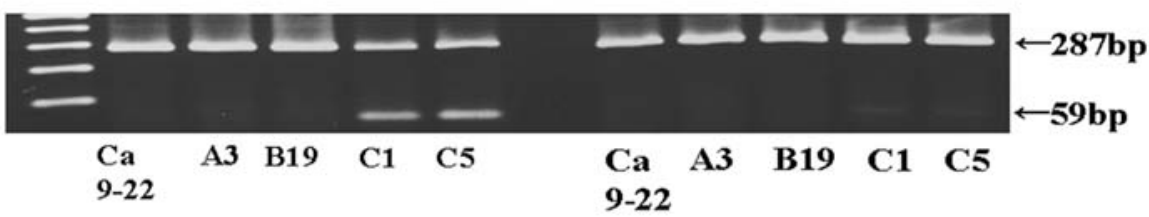

B
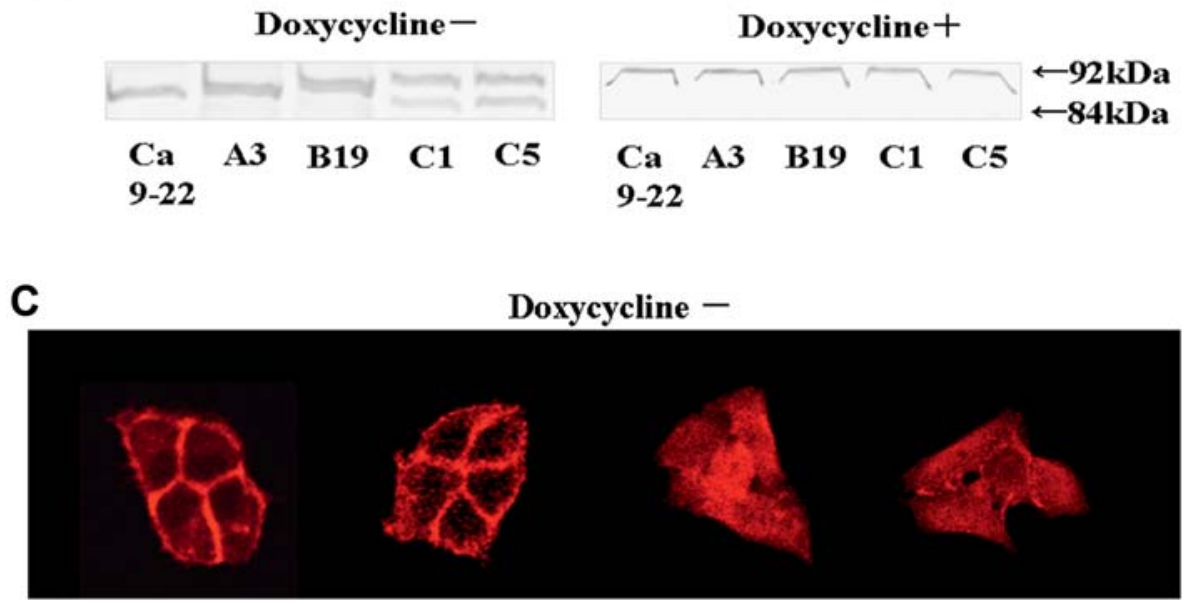

Doxycycline +

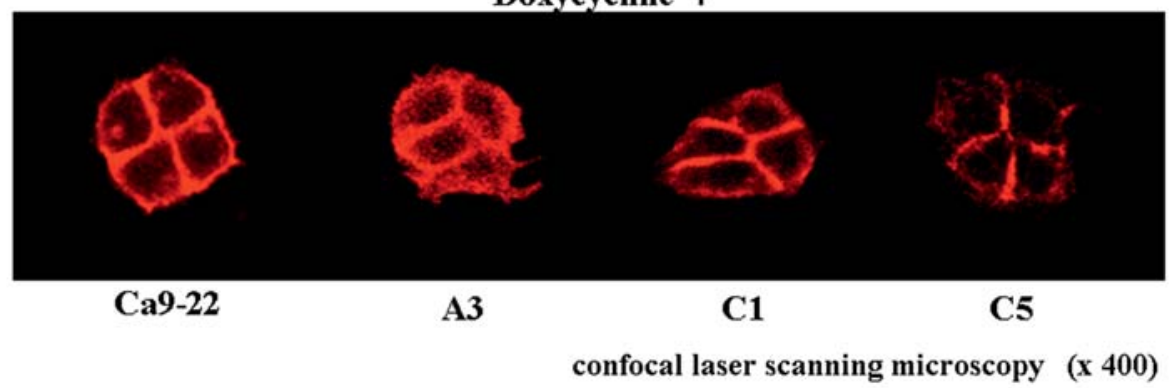

D

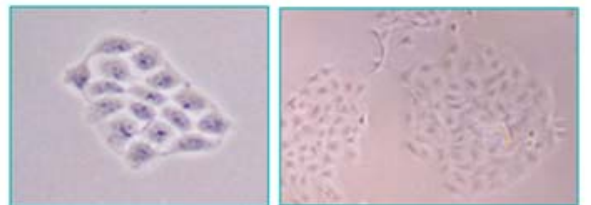

Ca9-22

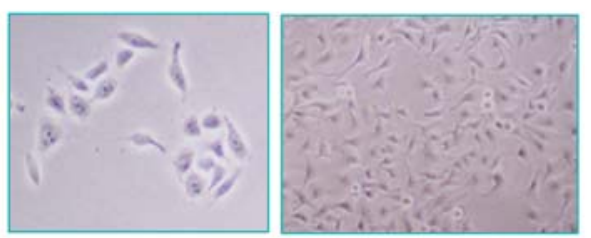

C1

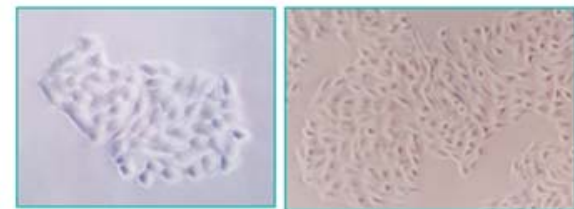

$\mathrm{A3}$

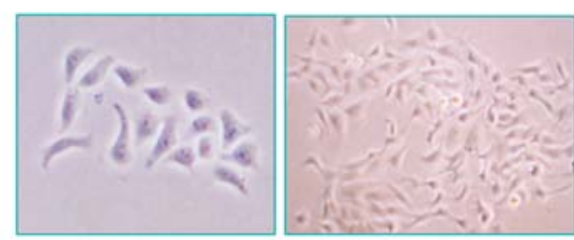

C5

Phases contrast microscopy $(\mathrm{x} 200, \mathrm{x} 100)$

Figure 2. Transfection of wild-type and mutant-type B-catenin genes into oral SCC cells. Ca9-22 cells were co-transfected with pUHD10-3 mutant B-catenin and pUHD15-1Neo, and geneticin-resistant cell lines C1 and C5 were obtained. B19 and A3 were obtained by transfecting Ca9-22 with pUHD10-3 wild-type B-catenin and pUHD10-3 vectors, respectively, in combination with pUHD15-1Neo. (A) The expression of B-catenin was examined by RT-PCR analysis with a set of primers spanning the exon 3 region of $\beta$-catenin, amplifying endogenous and wild-type $\beta$-catenin (287 bp) and mutant-type $\beta$-catenin (59 bp) DNA fragments in the presence or absence of $2 \mathrm{ng} / \mathrm{ml}$ doxycycline. (B) Endogenous and wild-type B-catenin (92 kDa) and mutant-type $\beta$-catenin (84 kDa) were detected by Western blotting. (C) The expression of $\beta$-catenin was examined by immunofluorescence staining. (D) The morphology of the transfectants was observed with a phase contrast microscope (magnification x200, right panel x100). 
A Invasion assay

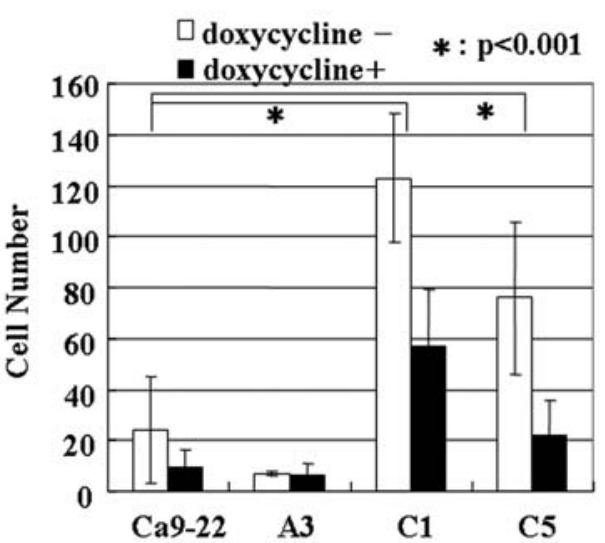

C

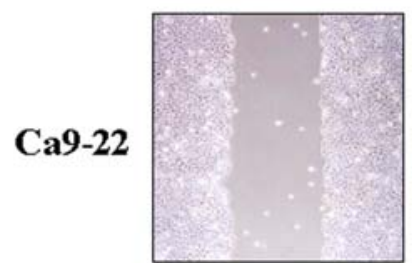

C1

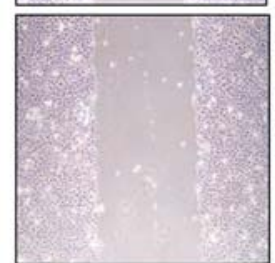

C5

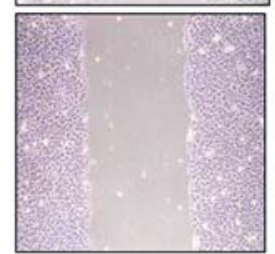

$18 \mathrm{~h}$
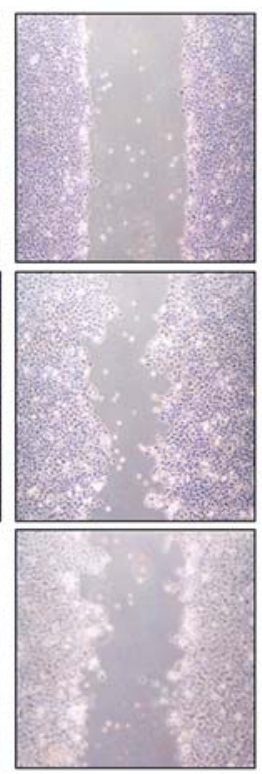

B Migration assay

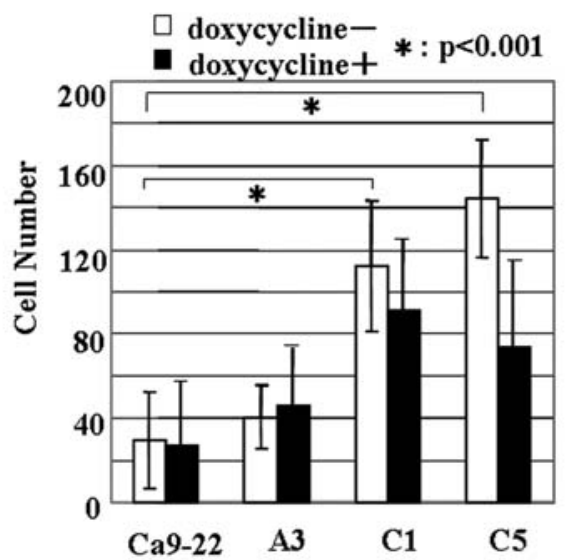

$36 \mathrm{~h}$

$48 h$
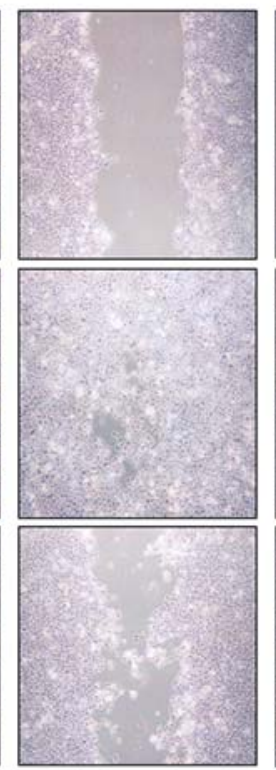

Figure 3. Enhancement of invasion and migration activities in the transfectants. (A) Invasion activity was measured in the presence or absence of 2 ng/ml doxycycline using a matrigel invasion chamber assay system. Each column indicates the mean \pm SD of three separate experiments. (B) Migration activity was measured in the presence or absence of $2 \mathrm{ng} / \mathrm{ml}$ doxycycline using a transwell chamber assay. (C) Migration activity was measured by wound healing assay. The monolayer of cells was scratched and the migration of cells was observed across the cleared surface of the dish. Wounded areas covered with migrating cells were observed using a phase contrast microscope for 48 h. ${ }^{*} \mathrm{p}<0.001$.

assay using a matrigel invasion chamber. The numbers of invading cells in $\mathrm{C} 1$ and $\mathrm{C} 5$ were 3 and 5 times higher, respectively, than that of the parental cell line Ca9-22. The difference was significant $(\mathrm{p}<0.001)$. Moreover, their invasion was suppressed markedly in the presence of $2 \mathrm{ng} / \mathrm{ml}$ doxycycline $(\mathrm{p}<0.001)$ (Fig. 3A).

The motility of Ca9-22 and transfectant cells was assessed by transwell chamber assay. The numbers of migrating cells in $\mathrm{C} 1$ and $\mathrm{C} 5$ were 4 and 5 times higher, respectively, than that of the parental cell line Ca9-22 (Fig. 3B). The difference was significant $(\mathrm{p}<0.001)$. In the presence of $2 \mathrm{ng} / \mathrm{ml}$ doxycycline, the migration activities were reduced markedly.

In the wound healing assay, the wounded area of the transfectants began to close at $18 \mathrm{~h}$ and was covered with migrating cells within $48 \mathrm{~h}$, while most of the injured area was left uncovered by $\mathrm{Ca} 9-22$ cells at $48 \mathrm{~h}$ (Fig. 3C).
$\beta$-catenin/Tcf-mediated transcriptional activity in the transfectants. To test the promoter activity of $\beta$-catenin/Tcf target genes that were regulated by the $\beta$-catenin/Tcf 4 complex, either pTOPflash or pFOPflash reporter constructs were transfected into Ca9-22, A3, C1 and C5 cells. The B-catenin/Tcf reporter activities in $\mathrm{C} 1$ and $\mathrm{C} 5$ were increased by 94 -fold and 35-fold, respectively, compared with that of the control $(\mathrm{p}<0.001)$ (Fig. 4A). When pTOPflash-transfected cells were incubated in the presence of $2 \mathrm{ng} / \mathrm{ml}$ doxycycline, the enhancement of $\beta$-catenin/Tcf reporter activity was not observed (Fig. 4B).

Expression of target genes of the Wnt/ $\beta$-catenin pathway in the transfectants. Whether mutant-type $\beta$-catenin could affect the expression of proliferation- and invasion-related target genes of the Wnt/ß-catenin pathway was examined using 

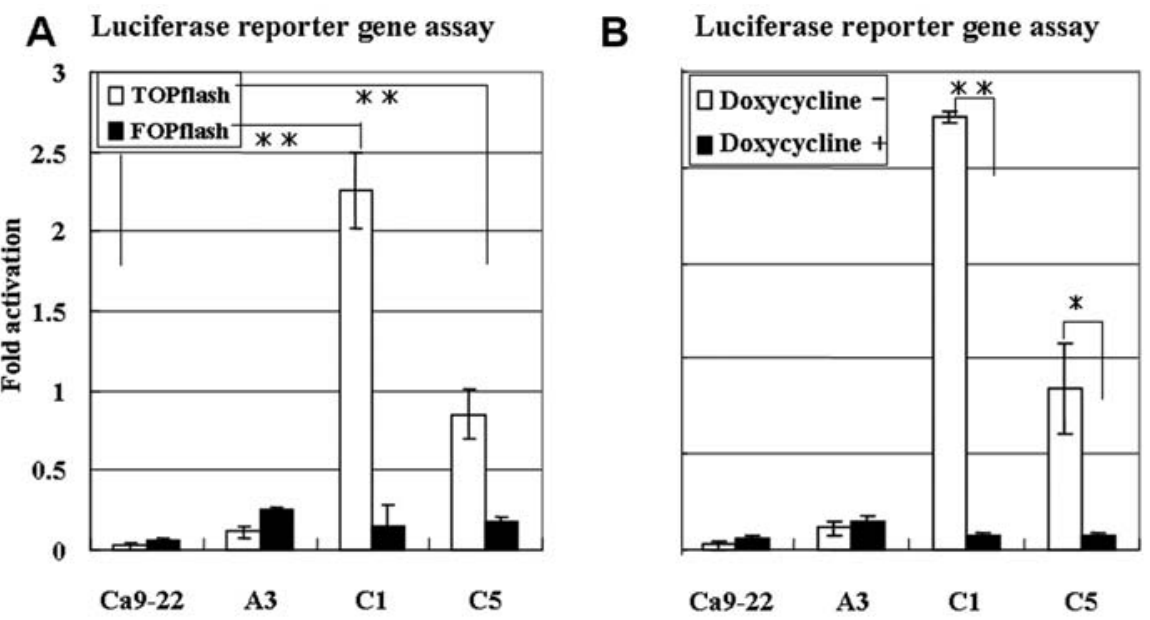

Figure 4. B-catenin/Tcf-mediated transcriptional activity in the transfectants. (A) pTOPflash or pFOPflash reporter constructs were transfected with the pRL-TK vector as an internal control into Ca9-22, A3, C1 and C5 cells, and luciferase activity was measured. Experiments were performed in triplicate. The results are expressed as means \pm SD. (B) Cells were transfected with pTOPflash reporter construct and cultured in the presence or absence of $2 \mathrm{ng} / \mathrm{ml}$ doxycycline. ${ }^{*} \mathrm{p}<0.01,{ }^{* *} \mathrm{p}<0.001$.

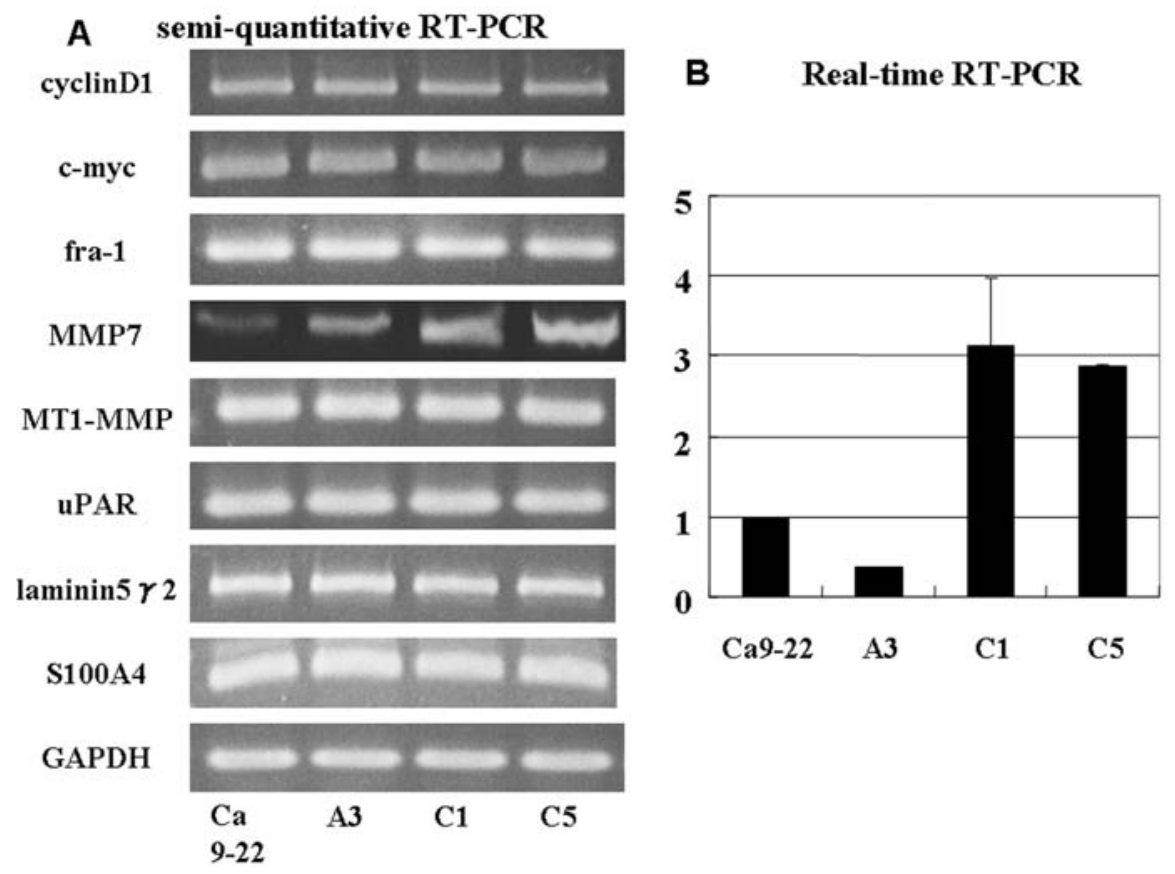

Figure 5. Expression of target genes of the Wnt/B-catenin pathway in the transfectants. (A) The expression of genes including cyclin D1, c-myc, fra-1, MMP-7, MT1-MMP, uPAR, laminin-5 $\gamma 2$ and S100A4 was measured by semi-quantitative RT-PCR. GAPDH was used as an internal control. (B) The mRNA levels of MMP-7 in Ca9-22, A3, C1 and C5 cells were measured by real-time RT-PCR. Each column indicates the mean \pm SD of three separate experiments.

semi-quantitative RT-PCR. Among genes including cyclin D1, c-myc, MT1-MMP, MMP-7, laminin-5 $\gamma 2$, uPAR and S100A4, the mRNA level of MMP-7 was increased in C1 and $\mathrm{C} 5$ cells compared with that of the Ca9-22 parental cells (Fig. 5A). In the presence of $2 \mathrm{ng} / \mathrm{ml}$ doxycycline, the expression level was decreased (data not shown). No significant changes were observed in the expression of other tested target genes of the Wnt/ß-catenin pathway.

Quantitative real-time RT-PCR analysis results showed that the expression of MMP-7 in $\mathrm{C} 1$ and $\mathrm{C} 5$ cells was 3 times higher than that of the parental $\mathrm{Ca} 9-22$ cells $(\mathrm{p}<0.001)$ (Fig. 5B).
Redistribution of E-cadherin and cytoskeleton change in the transfectants. B-catenin was originally identified as an intracellular cytoplasmic protein that interacts with the cytoplasmic domain of E-cadherin, providing anchorage to the cortical actin cytoskeleton via linkage to $\alpha$-catenin (25). The expression of E-cadherin in the parental cells and transfectants was examined by immunofluorescent antibody staining. In Ca9-22 cells, E-cadherin was specifically associated with the membrane, but it was distributed in both membrane and cytoplasm in C1 and C5 cells. Diffuse staining of E-cadherin was more prominent in $\mathrm{C} 1$ cells than in $\mathrm{C} 5$ cells (Fig. 6A). 


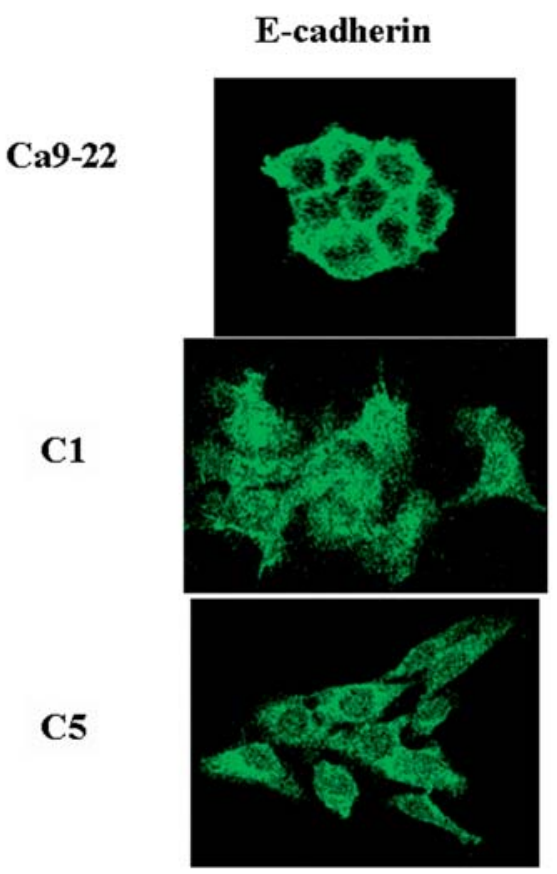

A

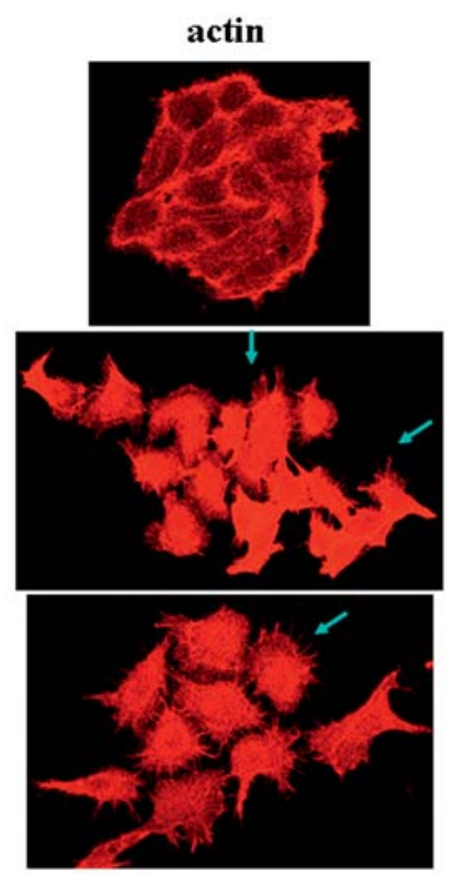

B

Figure 6. Redistribution of E-cadherin and cytoskeletal change in the transfectants. (A) E-cadherin was stained using mouse anti-E-cadherin monoclonal antibody and FITC-conjugated secondary antibody. (B) Actin filaments were stained using Alexa Fluor 546-Phalloidin. Confocal microscopy (x400).

\section{Cdc42}

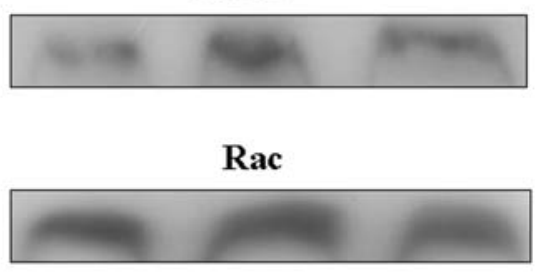

Rho

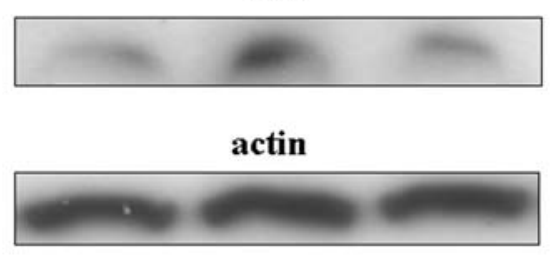

activeCdc42

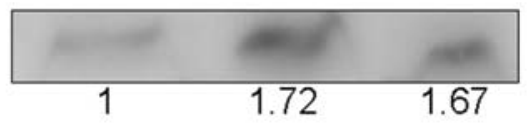

activeRac

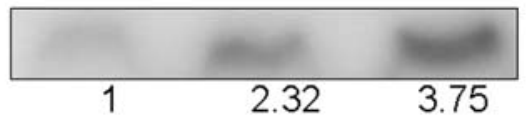

activeRho

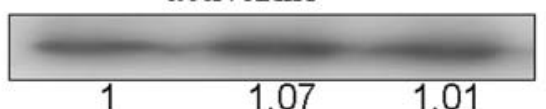

1.07

\section{Ca9-22 \\ C 1 \\ C 5 \\ Ca9-22 \\ C 1 \\ C 5}

Figure 7. Activation of Rho family members in the transfectants. Cell lysates were incubated with a GST fusion protein corresponding to either the p21binding domain (amino acid residues 67-150) of PAK1 or the Rho binding domain (amino acid residues 7-89) of Rhotekin, and the precipitates were collected. They were separated by SDS-PAGE and detected by immunoblotting with antibodies against Cdc42, Rac1 or Rho. The bands in three independent studies were scanned and their intensities were quantified using the public domain ImageJ program. Numerical values of the density in $\mathrm{C} 1$ and $\mathrm{C} 5$ cells were divided by values of the density in Ca9-22 cells.

Immunofluorescent staining of actin filaments using Alexa Fluor 546-conjugated phalloidin revealed the rearrangement of the actin cytoskeleton and filopodia-like protrusive structures were produced in $\mathrm{C} 1$ and $\mathrm{C} 5$ cells but not in parental $\mathrm{Ca} 9-22$ cells (Fig. 6B).

Activation of Rho family members in the transfectants. Rho family members including $\mathrm{Cdc} 42$, Rac and Rho GTPases have been reported to contribute to the rearrangement of actin filaments $(26,27)$. The levels of active $\mathrm{Cdc} 42$, Rac and Rho GTPases in the transfectants were measured by GTPase activity assays. When the density of each band showing active Rho family proteins was quantified using ImageJ software, active $\mathrm{Cdc} 42$ and Rac protein levels of $\mathrm{C} 1$ and $\mathrm{C} 5$ cells were higher than those of Ca9-22 cells (Fig. 7). There were no apparent differences in active Rho among these cell lines. 


\section{Discussion}

In Wnt signaling pathways, the ß-catenin pathway is one of the major oncogenic pathways and has been studied extensively in various human cancers such as colorectal, breast and thyroid cancer (28). Although there are a number of reports indicating the aberrant expression pattern of $\beta$-catenin in oral cancer tissues, the mechanism by which the Wnt/B-catenin pathway can contribute to the invasive behavior of oral SCC cells has not been studied intensively. In this regard, Yang et al (29) introduced an oncogenic $\beta$-catenin gene into head and neck squamous cell carcinoma (HNSCC) cells using a retrovirus vector and found that the transfectants were resistant to TNF- $\alpha$-induced apoptosis. The morphology changed from polygonal to spindle-shaped and exhibited higher invasive potential in a matrigel invasion assay, suggesting that the morphological alteration is associated with the invasive growth of HNSCC cells. In the present study, when a B-catenin gene that contained a mutation and was resistant to proteasome degradation was introduced into oral SCC Ca9-22 cells, two permanent cell lines showing spindle-like appearance were produced, although the parental Ca9-22 showed a polygonal shape. Because the growth potentials of the transfectants and the parental Ca9-22 cells were not different, it was considered that accumulation of transfected $\beta$-catenin in oral SCC cells modified the morphology of the cells, but proliferation was not affected. Furthermore, the transfectants had more invasive potential than the parental cells in a matrigel invasion assay. Thus, it was concluded that morphological changes of the transfectants were accompanied by the invasive growth of oral SCC cells, which was consistent with the results reported by Yang et al using HNSCC cells.

Owing to mutations in Wnt signaling components, the cytoplasmic level of $\beta$-catenin is elevated in a variety of human cancers, resulting in the constitutive activation of $\beta$-cateninTcf/Lef transcription and the expression of multiple key oncogenic proteins. After transfection of B-catenin into Ca9-22 cells, Tcf/Lef-specific transcriptional activity was increased and the enhancement was blunted in the presence of doxycycline, indicating that the high transcriptional activity of Tcf/Lef is induced by the expression of mutant B-catenin lacking the phosphorylation sites for GSK-3ß. A number of target genes activated in Wnt canonical pathways were identified. These include proliferation- and invasion-related genes, such as c-myc, cyclin D1 and MMP-7, as well cell-cell interaction genes, such as claudin- $1(8,9,12,26)$. In an attempt to detect possible target genes up-regulated by Tcf/Lef transcriptional activity, RT-PCR analysis was performed, and it was found that MMP-7 was up-regulated in the transfectants compared with that of the parental cells. Quantification by real-time PCR confirmed the elevation of MMP-7 transcription. Because MMP-7 is essential for the destruction of the basement membrane by proteolytic degradation, it is likely that the invasiveness of the transfectants can be ascribed, at least in part, to the expression of this proteinase.

EMT is a normal physiological process by which epithelial cells lose their relatively strong adhesiveness, become more mobile, and assume a spindle-shaped morphology resembling cells of mesenchymal origin. EMT facilitates migration and invasion of epithelial tumor cells and has been shown to increase metastatic potential in different types of malignant tumors $(31,32)$. The common biochemical change associated with EMT is the reduced expression of a key molecule of cell-cell adhesion, E-cadherin (33). The cytoplasmic domain of E-cadherin interacts with an intracellular cytoplasmic protein $\beta$-catenin. Indeed, Prasad et al (20) demonstrated the disorganization of E-cadherin- $\beta$-catenin complexes using invasive ductal carcinoma of breast, thereby supporting the notion that $\mathrm{Wnt} / \mathrm{B}$-catenin signaling is involved in the regulation of EMT. In the present study, we found that the transfectants showed a diffuse staining pattern of E-cadherin in the cytoplasm, although membranous localization of E-cadherin was demonstrated in the parental cells. The transfectants also had higher migration activity than the parental cells, which was accompanied by rearrangement of the actin cytoskeleton. Thus, it was considered that the accumulation of aberrant $\beta$-catenin in oral SCC cells induces redistribution of E-cadherin and rearrangement of the actin cytoskeleton, which induces EMT and provides a high migration activity to the transfectants.

The Rho family of GTPases regulates the cytoskeleton and cell adhesion (26,27). Moreover, Rho family members $\mathrm{Rac}$ and $\mathrm{Cdc} 42$ have been reported to regulate E-cadherindependent cellular adhesion through IQGAP1, which interacts with $\beta$-catenin, dissociating $\alpha$-catenin from the cadherincatenin complex, whereas RhoA can regulate E-cadherindependent adherence junctions indirectly by acting on the cytoskeleton (34). On the other hand, Asnaghi et al (35) reported that E-cadherin can negatively regulate cell proliferation and migration in non-small cell lung carcinoma by reducing the level of the predominant active forms of Rho family proteins, RhoA and Cdc42. They also stated that this regulation can be bidirectional. In the present study, we found that the levels of active $\mathrm{Cdc} 42$ and Rac were elevated in $\mathrm{C} 1$ and $\mathrm{C} 5$ cells with cytoplasmic accumulation of aberrant ß-catenin. Thus, active $\mathrm{Cdc} 42$ and Rac may negatively regulate the interaction between E-cadherin and B-catenin in the transfectants of mutant $B$-catenin. Alternatively, the dysfunction of E-cadherin caused by aberrant cytoplasmic expression of ß-catenin may permit an increase in active $\mathrm{Cdc} 42$.

In conclusion, we indicated that aberrant cytoplasmic accumulation of $\beta$-catenin can induce Tcf/Lef-mediated transcriptional activity and up-regulate MMP-7, and that it induced Rho family member-mediated rearrangement of the actin cytoskeleton and redistribution of E-cadherin. This would result in EMT of oral SCC cells that would increase the levels of invasion and migration. In oral SCC, metastasis occurs in approximate $30 \%$ of patients, which is a critical factor for the patient prognosis. Wnt/ß-catenin signaling seems to be an attractive molecular target for developing effective therapies for many cancers and novel inhibitors for this signaling have been reported $(36,37)$. Suppression of the canonical $\beta$-catenin pathway could be a useful approach to prevent metastasis of oral SCC cells.

\section{Acknowledgements}

This study was funded by Grants-in-Aid for Scientific Research<KAKENHI $>$ from the Japanese Society for the Promotion of Science: No.19592293. We would like to thank 
Dr Nakamura Yusuke (Tokyo University, Japan) for providing B-catenin cDNA cloned into pUHD10-3 and pUHD10-3/ wtTcf-4 or pcDNA3.1+/dnTcf-4.

\section{References}

1. Veeman MT, Axeirod JD and Moon RT: A second canonical Functions and mechanisms of beta-catenin-independent Wnt signaling. Dev Cell 5: 367-377, 2003.

2. Nelson WJ and Nusse R: Convergence of Wnt, beta-catenin and cadherin pathways. Science 303: 1483-1487, 2004.

3. Kikuchi A: Roles of Axin in the Wnt signaling pathway. Cell Signal 11: 777-788, 1999.

4. Liu C, Li Y, Semenov M, Han C, Baeg GH, Tan Y, Zhang Z, Lin $\mathrm{X}$ and $\mathrm{He} \mathrm{X}$ : Control of $B$-catenin phosphorylation/ degradation by a dual-kinase mechanism. Cell 108: 837-847, 2002.

5. Kitagawa S, Hatakeyama S, Shirane M, Matsumoto M, Ishida N, Hattori K, Nakamichi I, Kikuchi A, Nakayama KI and Nakayama K: An F-box protein, FWD1, mediates ubiquitindependent proteolysis of B-catenin. EMBO J 18: 2401-2410, 1999.

6. Polakis P: Wnt signaling and cancer. Genes Dev 14: 1837-1851, 2000.

7. Huristone A and Clevers H: T-cell factors: turn-ons and turnoffs. EMBO J 21: 2303-2311, 2002.

8. He TC, Sparks AB, Rago C, Hermeking H, Zawel L, Da Costa LT, Morin PJ, Vogelstein B and Kinzler KW: Identification of $c-m y c$ as a target of the APC pathway. Science 281: 1509-1512, 1998.

9. Tetsu $\mathrm{O}$ and McCormick F: Beta-catenin regulates expression of cyclin D1 in colon carcinoma cells. Nature 398: 422-426, 1999.

10. Mann B, Gelos M, Siedow A, Hanski ML, Gratchev A, Ilyas M, Bodmer WF, Moyer MP, Riecken EO, Buhr HJ and Hanski C: Target genes of beta-catenin-T cell factor/lymphoid-enhancerfactor signaling in human colorectal carcinomas. Proc Natl Acad Sci USA 96: 1603-1608, 1999.

11. Takahashi M, Tsunoda T, Seiki M, Nakamura Y and Furukawa Y: Identification of membrane-type matrix metalloproteinase-1 as a target of the B-catenin/Tcf 4 complex in human colorectal cancers. Oncogene 21: 5861-5867, 2002.

12. Brabletz T, Jung A, Dag S, Hlubek F and Kirchner T: B-catenin regulates the expression of the matrix metalloproteinase-7 in human colorectal cancer. Am J Pathol 155: 1033-1038, 1999.

13. Morin PJ, Sparks AB, Korinck V, Barker N, Clevers H, Vogelstein B and Kinzler KW: Activation of beta-catenin-Tcf signaling in colon cancer by mutation in beta-catenin or APC. Science 275: 1787-1790, 1997.

14. Rubinfeld B, Robbins P, El-Gamil M, Albert I, Porfiri E and Polakis P: Stabilization of beta-catenin by genetic defects in melanoma cell lines. Science 275: 1790-1792, 1997.

15. Lo Muzio L, Staibano S, Pannone G, Grieco M, Mignogna MD, Cerrato A, Testa MF and De Rosa G: Beta- and gamma-catenin expression in oral squamous cell carcinomas. Anticancer Res 19: 3817-3826, 1999.

16. Gao S, Eiberg H, Krogdahl A, Liu CJ and Sorensen JA: Cytoplasmic expression of E-cadherin and beta-catenin correlated with $\mathrm{LOH}$ and hypermethylation of the APC gene in oral squamous cell carcinomas. J Oral Pathol Med 34: 116-119, 2005.

17. Iwai S, Katagiri W, Kong C, Amekawa S, Nakazawa M and Yura Y: Mutation of the APC, beta-catenin, and axin1 genes and cytoplasmic accumulation of beta-catenin in oral squamous cell carcinoma. J Cancer Res Clin Oncol 15: 1-10, 2005.

18. Schmalhofer O, Brabletz S and Brabletz T: E-cadherin, betacatenin, and ZEB1 in malignant progression of cancer. Cancer Metastasis Rev 28: 151-166, 2009.

19. Lopes FF, Da Costa Miguel MC, Pereira AL, Da Cruz MC, De Almeida Freitas R, Pinto LP and De Souza LB: Changes in immunoexpression of E-cadherin and beta-catenin in oral squamous cell carcinoma with and without nodal metastasis. Ann Diagn Pathol 13: 22-29, 2009.
20. Prasad CP, Mirza S, Sharma G, Prashad R, DattaGupta S, Rath G and Ralhan R: Epigenetic alterations of $\mathrm{CDH} 1$ and APC genes: relationship with activation of Wnt/beta-catenin pathway in invasive ductal carcinoma of breast. Life Sci 83: 318-325, 2008.

21. Tanaka N, Odajima T, Ogi K, Ikeda T and Satoh M: Expression of E-cadherin, alpha-catenin and beta-catenin in the process of lymph node metastasis in oral squamous cell carcinoma. Br J Cancer 89: 557-563, 2003

22. Kurtz KA, Hoffman HT, Zimmerman MB and Robinson RA: Decreased E-cadherin but not beta-catenin expression is associated with vascular invasion and decreased survival in head and neck squamous carcinomas. Otolaryngol Head Neck Surg 134: 142-146, 2006.

23. Horikoshi M, Kinura $\mathrm{Y}$, Nagura $\mathrm{H}$, Ono $\mathrm{T}$ and Ito $\mathrm{H}$ : A new human cell line derived from human carcinoma of the gingival. Jpn J Oral Maxillofac Surg 20: 100-106, 1974.

24. Nagasawa Y, Miyoshi Y, Iwao K, Shinomura Y, Matsuzawa Y and Nakamura Y: Transformation and morphological changes of murine L cells by transfection with a mutated form of betacatenin. Cancer Res 59: 3539-3542, 1999.

25. Kemler R: From cadherins to catenins: cytoplasmic protein interactions and regulation of cell adhesion. Trends Genet 9: 317-322, 1993

26. Jaffe A and Hall A: Rho GTPases: biochemistry and biology. Annu Rev Cell Dev Biol 21: 247-269, 2005.

27. Price LS and Collard JG: Regulation of the cytoskeleton by Rho-family GTPases: implications for tumor cell invasion. Semin Cancer Biol 11: 167-173, 2001.

28. Giles RH, van Es JH and Clevers H: Caught up in a Wnt storm: Wnt signaling in cancer. Biochim Biophys Acta 1653: 1-24, 2003.

29. Yang F, Zeng Q, Yu G, Li S and Wang CY: Wnt/B-catenin signaling inhibits death receptor-mediated apoptosis and promotes invasive growth of HNSCC. Cell Signal 18: 679-687, 2005.

30. Miwa N, Furuse M, Tsukita S, Niikawa N, Nakamura Y and Furukawa Y: Involvement of claudin-1 in the beta-catenin/Tcf signaling pathway and its frequent upregulation in human colorectal cancers. Oncol Res 12: 469-476, 2001.

31. Thiery JP, Acloque H, Huang RY and Nieto MA: Epithelialmesenchymal transitions in development and disease. Cell 139: 871-890, 2009.

32. Xue C, Plieth D, Venkov C, Xu C and Neilson EG: The gatekeeper effect of epithelial-mesenchymal transition regulates the frequency of breast cancer metastasis. Cancer Res 63: 3386-3394, 2003.

33. Peinado H, Portillo F and Cano A: Transcriptional regulation of cadherins during development and carcinogenesis. Int J Dev Biol 48: 365-375, 2004.

34. Fukata M, Nakagawa M and Kaibuchi K: Roles of Rho-family GTPases in cell polarisation and directional migration. Curr Opin Cell Biol 15: 590-597, 2003.

35. Asnaghi L, Vass WC, Quadri R, Day PM, Qian X, Braverman R, Papageorge AG and Lowy DR: E-cadherin negatively regulates neoplastic growth in non-small cell lung cancer: role of Rho GTPases. Oncogene 15: 1-12, 2010.

36. Takahashi-Yanaga F and Sasaguri T: Drug development targeting the glycogen synthase kinase-3beta (GSK-3beta)-mediated signal transduction pathway: inhibitors of the Wnt/beta-catenin signaling pathway as novel anticancer drugs. J Pharmacol Sci 109: 179-183, 2009.

37. Choi H, Gwak J, Cho M, Ryu MJ, Lee JH, Kim SK, Kim YH, Lee GW, Yun MY, Cuong NM, Shin JG, Song GY and Oh S: Murrayafoline A attenuates the Wnt/beta-catenin pathway by promoting the degradation of intracellular beta-catenin proteins. Biochem Biophys Res Commun 391: 915-920, 2010. 